\title{
Microfestivaleiros Histórias e aventuras de alcatifa
}

\section{Susana Chicó}
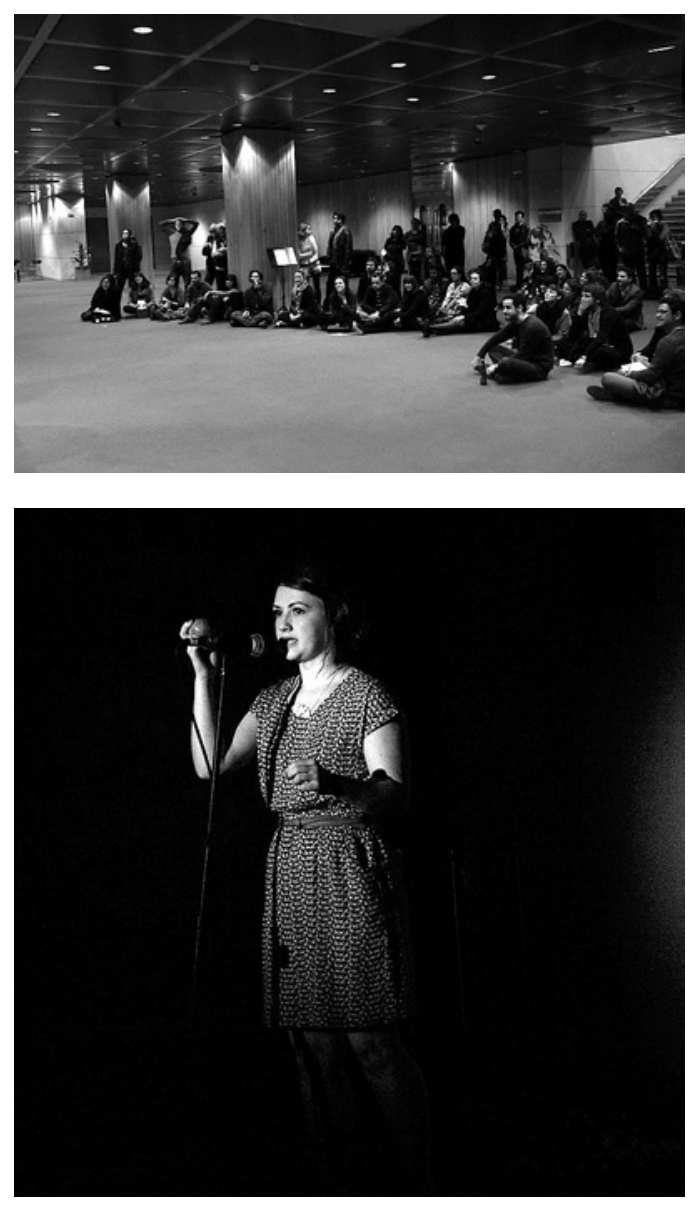

No passado mês de Fevereiro a Culturgest acolheu o Forest Fringe, um (micro) festival de artes performativas chegado do Reino Unido. Esta iniciativa é dirigida pelos jovens artistas Deborah Pearson e Andy Field, e teve a sua primeira edição há 5 anos, no café Forest, em Edimburgo. Desde então, o festival tem decorrido neste local, paralelamente ao Festival de Edimburgo, oferecendo uma programação alternativa e mais barata a públicos dispostos a arriscar num formato menos empacotado.

0 Forest Fringe acolhe o trabalho de artistas da live art, do teatro experimental e da performance britânicas, e tem vindo a afirmar-se pelo seu perfil experimental e invulgar. A sua estratégia administrativa torna este festival num evento fora do habitual, sendo dirigido por artistas e não tendo fins lucrativos. É uma organização totalmente independente e auto-sustentável que se baseia na mais simples transacção: a partilha. Aqui, partilham-se espaços, materiais, ideias, saberes e tarefas, organizando-se

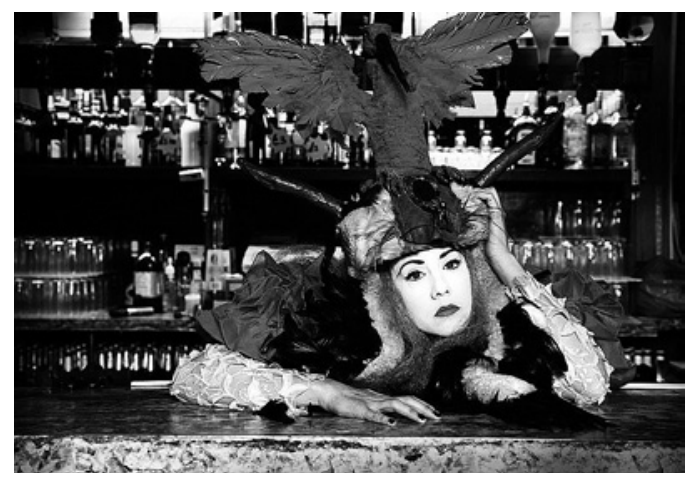

\section{Ambiente geral na \\ Culturgest durante a apresentação de um espectáculo. \\ Work in progress de Bryony Kimmings, 2012 (Bryony Kimmings).}

colectivamente um contexto onde os artistas podem experimentar e mostrar gratuitamente o seu trabalho. Ao longo dos anos, o projecto tem vindo a crescer, e as viagens pelo Reino Unido têm vindo a aumentar, sobretudo desde a criação de uma versão mais portátil deste festival: o microfestival. Estes microfestivais têm vindo a evidenciar vários artistas no panorama britânico, comprovando-se assim o sucesso de um modelo de gestão centrado na autonomia do artista. 0 director Andy Field acredita mesmo que uma das competências lesadas pela estabilização do sector cultural inglês foi a capacidade de sobrevivência que todos os artistas devem possuir para atravessar o seu contexto sócio-económico. Para Field, cada um deles deve ser empreendedor e criar recursos para se adaptar às suas circunstâncias. 0 director não defende - com esta posição - a abolição dos apoios e sistemas formais da produção cultural, defende, sim, o valioso proveito que a criação independente de um projecto, sem recurso a subsídios ou instituições, pode trazer. Muitos dos artistas, que constituem este projecto, estão já a criar a sua própria programação, pois Andy Field e Deborah Pearson investem e confiam na criatividade desta comunidade artística, e, sobretudo, na sua proactividade.

A primeira apresentação internacional do Forest Fringe foi precisamente na Culturgest de Lisboa, e marca mais uma conquista deste projecto: o princípio do seu crescimento além-fronteiras.

\section{Simetria de opostos: Abertura e fecho}

Os artistas estiveram durante três dias instalados em vários espaços do edifício. Entre as sete da tarde e a meia-noite, o público pôde ver uma amostra do trabalho que este festival acolhe, e experienciar uma Culturgest mais informal e festivaleira. 0 público foi também convidado a explorar a Travelling Sounds Library, que se compunha de peças de som independentes espalhadas em livros ocos pelos vários cantos do foyer principal, e podia ainda ver entre 


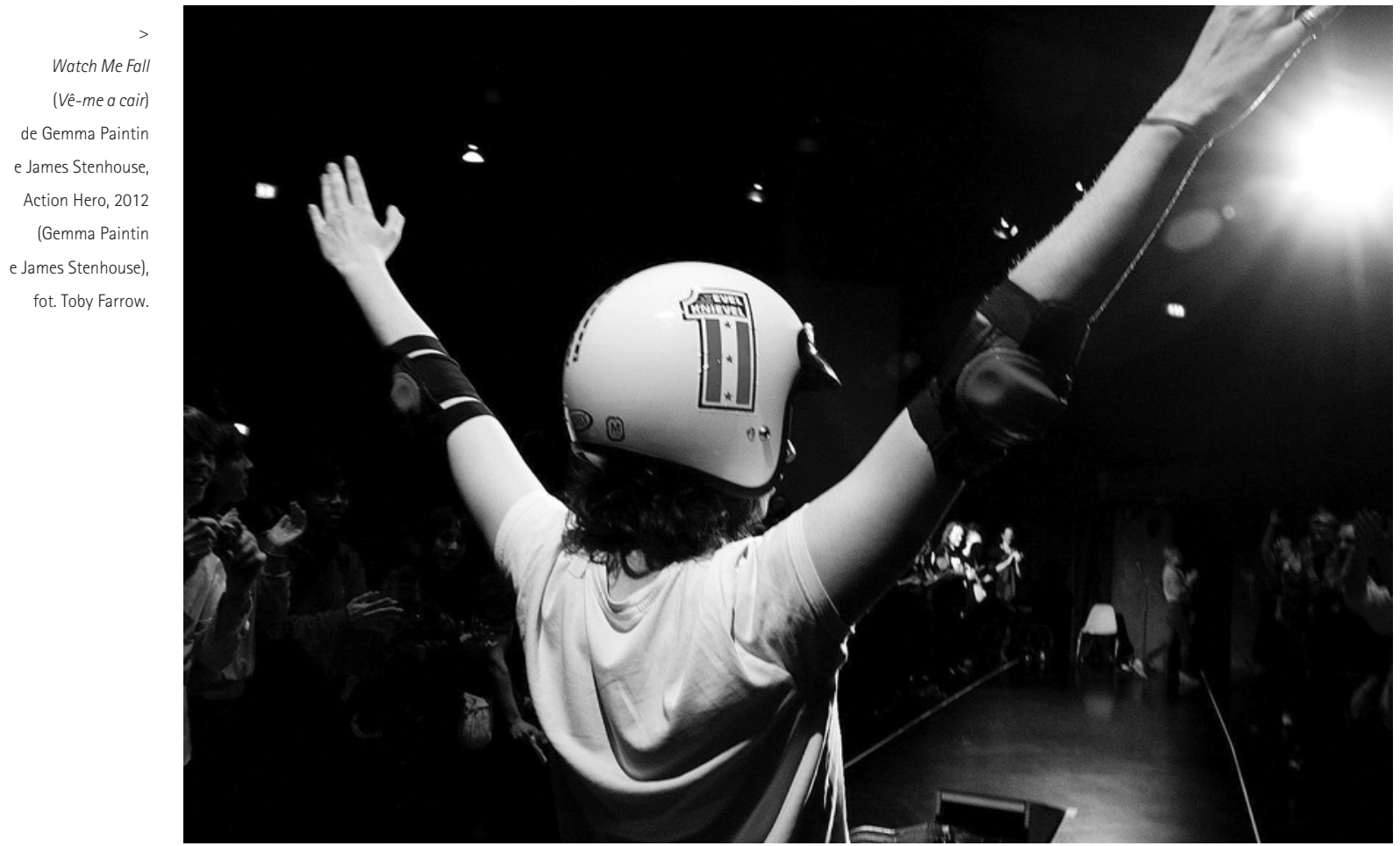

espectáculos as instalações de Tim Etchells e Andy Field, e o filme de Kieran Hurley e Gary McNair.

Os dois espectáculos, que abriram e concluíram este microfestival, são criações que foram experimentadas e desenvolvidas no Forest Fringe. Watch Me Fall dos Action Hero e Growing Old With You dos Search Party foram ambos a presentados em formato work in progress em duas das edições do festival: Watch Me Fall em 2008 e Growing Old With You em 2010.

Deborah Pearson e Andy Field parecem ter escolhido estes dois espectáculos como exemplo da consistência e estabilidade do seu projecto. Ambas as companhias são formadas por casais que desenvolvem nestes projectos estéticas praticamente opostas. Enquanto os Action Hero apostam numa comunicação recheada de iconografia americana e de sonoridades gritantes, os Search Party exploram as possibilidades cénicas da passagem do tempo através do silêncio e de um despojamento cénico misterioso feito de cartografias desenhadas a sal.

A dicotomia sonora e visual, que ocorre entre estes dois espectáculos, marca uma preocupação programática que insiste na variedade de linguagens artísticas. Além disso, esta abertura e esta conclusão apresentam e encerram uma temática implícita a todo o microfestival: os géneros.

A abertura coube aos Action Hero (Gemma Paintin e James Stenhouse) que apresentaram Watch Me Fall na garagem da Culturgest. 0 espectáculo foi inspirado nos daredevilsamericanos, e é o primeiro de uma trilogia sobre a iconografia do sexo masculino. Os artistas tomaram o salto de Evel Knievel à fonte do Caesars' Palace em Las Vegas como exemplo paradigmático da bravura masculina, prometendo ao seu público um feito semelhante. $\dot{A}$ chegada, os actores distribuiam Coca-Colas e máquinas fotográficas descartáveis pelo público, que, por sua vez, ficava de pé a assistir e a aplaudir a esta longa e barulhenta promessa. 0 actor dizia que daria um salto na sua mota (que na realidade é uma bicicleta de crianças) de uma distância de doze barris, vendado, dentro de um saco, a arder.

0 que inicialmente parece uma paródia ao espectáculo de morte americano, torna-se gradualmente numa raivosa demonstração de violência gratuita que procura constantemente a cumplicidade do público. Os actores entregavam-se a actos absurdos que procuravam retratar a força masculina e a sua respectiva denegrição feminina. Exemplos disso são a primitiva sessão de pontapés à cabeça do actor, ou o obsceno e vagamente pornográfico despejo de garrafas de Coca-Cola na boca da actriz. No final do espectáculo, o actor saltava finalmente com a sua pequena bicicleta sobre um repuxo artesanal feito com Coca-Cola e Mentos, voando enfim para a sua queda. Os Action Hero confrontam o público com a sua responsabilidade sobre os riscos e violência apresentados em cena. Watch Me Fall remete para os primórdios do espectáculo de morte, lembrando o seu papel na construção iconográfica do macho.

Por sua vez, os Search Party terminaram o festival contrariando a furiosa vitalidade da sua abertura com uma silenciosa e depurada reflexão sobre o envelhecimento. Growing Old With You é um projecto que se iniciou em 2010, por ocasião da proximidade do trigésimo aniversário dos artistas, e que será recriado num novo espectáculo a cada dez anos para o resto das suas vidas. Em Growing Old With You, Pete Philips e Jodie Hawkes, pretendem traçar o percurso de uma vida inteira em tempo real. Para tal, utilizam elementos cénicos e interpretativos que remetem para a memória comum e para a abstracção de um futuro vindouro. Ao partilharem gestos e palavras tratam o conceito da dualidade das vivências comuns, a presença de uma câmara de filmar marca a captação de histórias passadas em tempo presente, e ao cartografarem num chão de sal as suas pegadas e movimentos criam um percurso temporal abstracto e incerto, aquele que se perde nos silêncios e cumplicidades. 


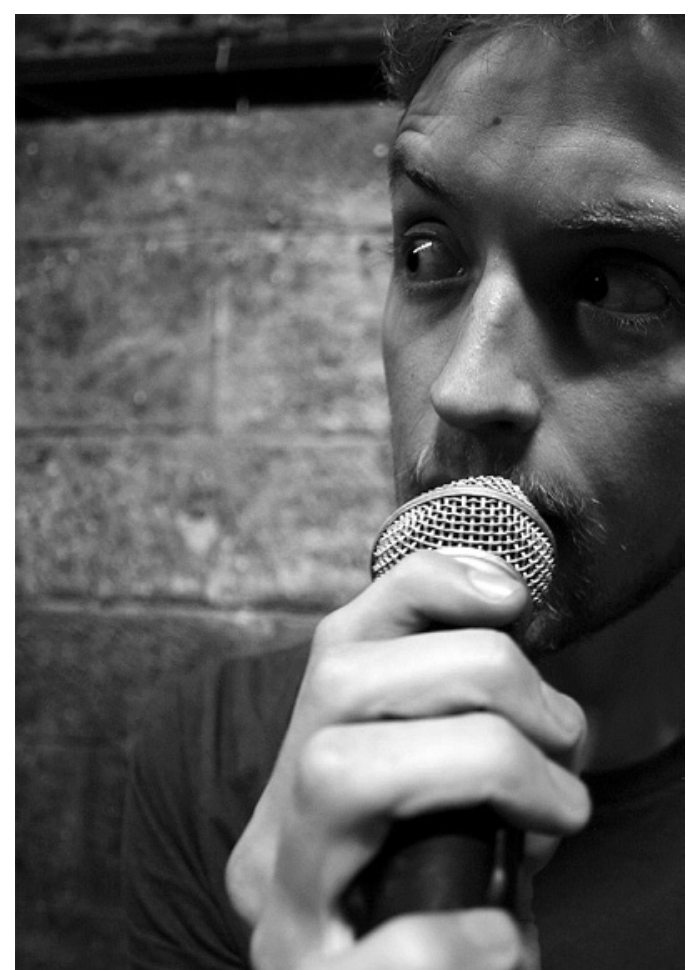

0 festival fechou com esta muda reflexão sobre os conceitos de idade, acumulação de experiências e dualidade, encerrando o evento com uma tonalidade metafísica e enigmática.

\section{Aventuras: Correrias, computadores e corações} despedaçados

Entre a abertura e o segundo espectáculo, o público foi convidado a assistir a pequenas experiências muito interessantes criadas numa semana de trabalho nos espaços da Culturgest pelos artistas Jenna Watt, Bryony Kimmings e Mamoru Iriguchi. Os portugueses André E. Teodósio \&t Cão Solteiro também se integraram no microfestival realizando uma audição para o trabalho de Top Models Paula Sá Nogueira (um bestiário) que estreou em Março no mesmo espaço.

Na rampa das galerias, Jenna Watt apresentou ao público uma experiência do processo criativo de Flâneurs, o seu próximo trabalho que estreará este Verão no Festival Fringe de Edimburgo. Nesta experiência, a artista contava individualmente a cada espectador uma história sobre violação, e a esse de seguida encomendava uma perseguição até ao fim da rampa para testar as suas capacidades de fuga. 0 público, surpreendido, observava a artista a tentar escapar do espectador, soltavam-se até gargalhadas e risos, pois os observadores desconheciam o contexto desta acção. 0 desfecho da perseguição cabia precisamente a um espectador que soprava um apito entregue pela artista. Jenna Watt é uma artista conhecida por explorar a violência, o risco e a interacção no seu trabalho performativo. Esta pequena experiência realizada para Flâuneurs revela estas mesmas três matrizes. 0 título Flâuneurs significa "passeantes", pessoas que flanam, ou seja, que andam sem destino experienciando as cidades com longos passeios. Jenna Watt pretende com este projecto explorar a natureza da violência em espaços públicos utilizando a psicogeografia (um campo da geografia que estuda os efeitos do ambiente
Hitch (Boleia), de Kieran Hurley, 2012 (Keiran Hurley), fot. Niall Walker. geográfico urbano nas emoções e comportamentos das pessoas) e ainda desconstruir o "by-stander effect" (um fenómeno psicológico que prova que quanto maior é o número de pessoas presentes numa situação violenta, menor é a probabilidade de alguém ir em socorro da vítima). Ao pedir um ataque e ao confiar a sua salvação a membros do público, Jenna Watt reivindica uma intervenção activa àqueles que assistem ao seu próprio risco e consequente vulnerabilidade. Uma experiência interessante que permitiu que a artista sentisse na pele os riscos de um ataque num local público, e testasse também a sua força perante esta situação.

Simultaneamente, o japonês Mamoru Iriguchi - zoólogo incompetente, cenógrafo premiado, designer gráfico e performer auto-didacta - manobrava monitores, projectores e cursores numa pequena sala, criando uma interacção visual com o público. Lá, foi apresentada uma performance multimédia - Journey From a Man to a Woman - que tinha a mudança de sexo como pretexto temático.

Iriguchi criou uma espécie de palestra/cabaret high tech no/na qual se reflectia sobre a evolução das espécies, questões de género e fantasias eróticas. Um tema incontornavelmente fisico foi transformado numa viagem entre o seu próprio corpo e as imagens virtuais exibidas.

Desta forma, o artista confundia o masculino com o feminino, e o real com o virtual, metendo pelo meio descrições biológicas sobre baleias e música pop dos anos 50 a marcar um ritmo humorístico e terno a esta fusão surrealista de sexos e de mundos. Para a concretização técnica desta experiência interactiva, Iriguchi sobrepunha um monitor sobre o seu corpo, monitor este que mostrava um cartoon tosco do corpo de uma mulher, que depois se transformava num cartoon tosco do corpo de um homem, e, seguidamente, em corpos hibridos que envolviam lingerie e genitais desproporcionados. Estes cartoons apareciam mais tarde como objectos reais em tiradas ilusionistas surpreendentes, que faziam com que o plano digital e o plano real se fundissem num breve momento de magia. Iriguchi apresentou uma cómica, e levemente inquietante, experiência sobre transformações e transições, sugerindo uma evolução da espécie humana para um estado indefinido como o estado sexual apresentado na sua viagem.

Desconstrói-se nesta exótica experiência nipónica a ideia de uma utilização da tecnologia em detrimento dos recursos criativos do corpo, equilibrando os dois mundos através de uma entrega total à sua fruição inocente e fantasista.

Desta absurda aventura multimédia, passou-se a uma outra absurda aventura, desta vez com um carácter mais emocional. A inglesa Bryony Kimmings apresentou uma série de pequenos números performativos que eram parte integrante do desenvolvimento de Heartache. Heartbreak., o seu próximo espectáculo sobre uma das mais traumáticas e universais experiências humanas: o desgosto amoroso. Bryony Kimmings tem tido um sucesso crescente no Reino Unido, tendo sido inclusivamente distinguida com um 
Growing Old With You (Envelhecer contigo), de Pete Phillips e Jodie Hawkes, Search Party, 2012 (Jodie Hawkes e Pete Phillips).

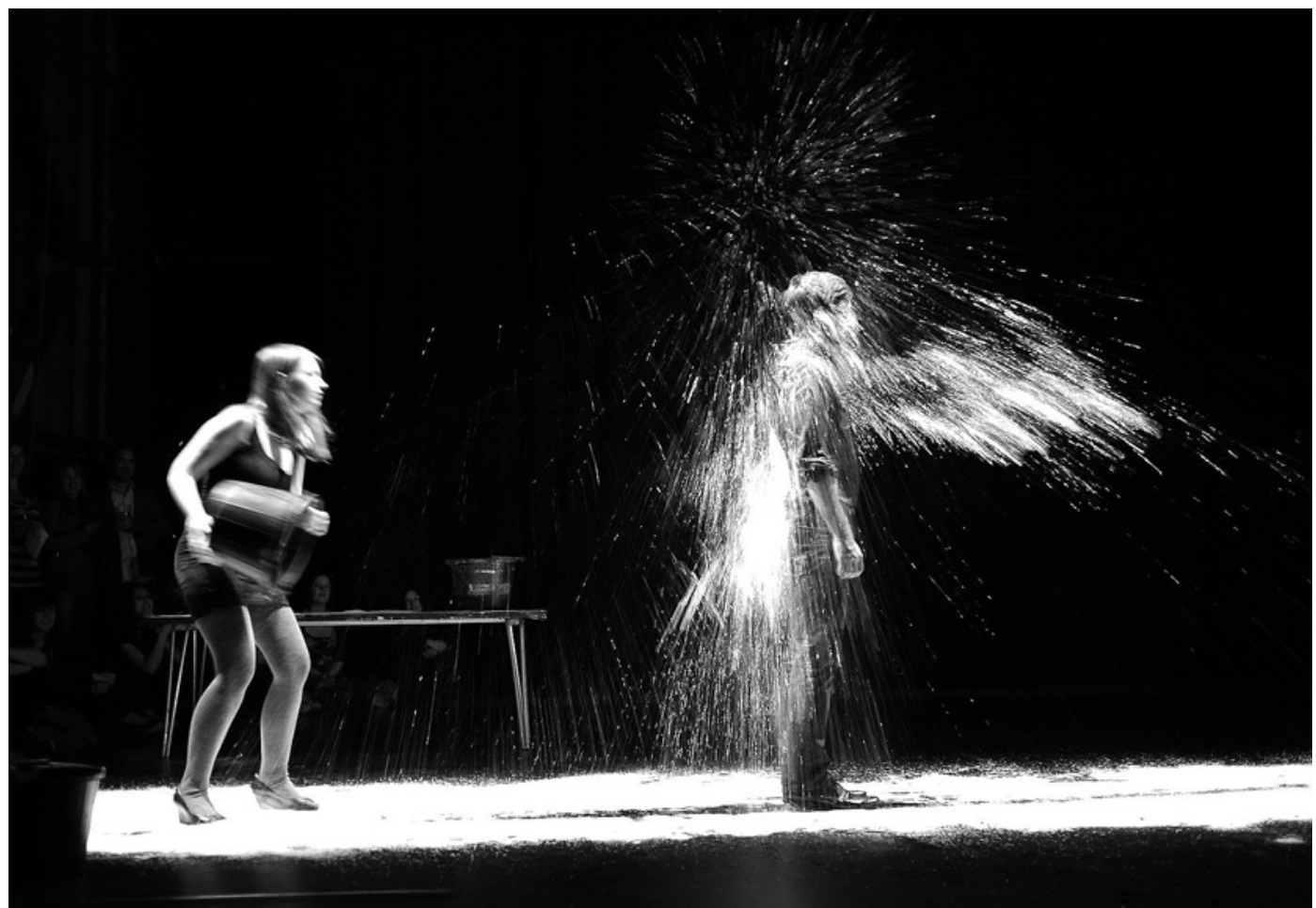

Prémio Total Theatre pela qualidade inovadora do seu espectáculo Sex Idiot, um excêntrico e desavergonhado monólogo construido a partir das desventuras sexuais da artista. Este espectáculo é exemplo das criações extravagantes e multidisciplinares que caracterizam o trabalho de Kimmings, cruzando as suas reais (in)confidências com pequenos números de dança, canto, e spoken word numa narrativa desinibida e cómica.

Bryony Kimmings manteve a mesma estratégia criativa nesta experiência criada para a Culturgest, recorrendo uma vez mais a uma persona descontrolada, embrenhada num solitário consolo alcoólico. Atrás do balcão do bengaleiro Kimmings começava por dançar e cantar ao som de músicas lamechas, criando o esboço de um universo ficcional ébrio e disparatado. Bebia champanhe por uma garrafa, e comia gelado de uma taça exageradamente grande. 0 seu vestuário parecia um fato de carnaval de uma espécie de princesa medieval futurista apresentando-se como uma personagem anacrónica que exprimia duas posições românticas antagónicas. Bryony Kimmings usava um chapéu bicudo de dama medieval, um longo vestido branco, e uma cabeleira cor-de-rosa, que no seu conjunto se referiam a arquétipos femininos antigos e modernos. Estes pequenos apontamentos visuais criaram sinteticamente um conflito entre paradigmas opostos: o encontro de uma donzela medieval com uma barbie punkrock num só corpo alcoolizado, dividido entre uma fantasia romântica que se refere a príncipes encantados, e uma atitude independente e rebelde. Esta experiência resultou numa cómica abordagem aos diferentes estados emocionais do desgosto amoroso criada com lugares comuns e gestos idiotas.

Histórias: A intimidade imediata da narrativa No momento Histórias, o público tinha de escolher uma entre duas histórias: Like You Were Before de Deborah Pearson e Hitch de Kieran Hurley. Ambos os espectáculos foram construídos a partir de experiências pessoais dos artistas. Kieran Hurley propôs uma proactiva história política ao relatar uma viagem à boleia até à $35^{\text {a }}$ reunião de cúpula do G8, e Deborah Pearson optou por uma envolvência mais intima e meditativa que reflectia sobre os acontecimentos gravados num vídeo caseiro sobre o seu último dia no Canadá, sua terra natal, antes de partir para Londres em 2005.

Deborah Pearson subiu ao palco com um cumprimento simpático e caloroso, e iniciou a sua narrativa propondo um olhar do passado como uma viagem de comboio ao contrário, ou seja, uma viagem em que o passageiro olha pela janela a paisagem que deixou para trás. 0 vídeo era projectado numa tela e Pearson ia parando o seu visionamento para decifrar a importância dos momentos, das conversas e das pessoas que figuravam no vídeo: amigos, pais, objectos e paisagens. Sempre que a artista aparecia no vídeo, falava por cima da sua própria voz repetindo no presente as palavras e sons do passado. Esta sobreposição da voz presente e da voz gravada causava um efeito constrangedor que marcava uma intrusão embaraçosa e o impossível regresso ao passado. Este voice over e uma pequena dança foram os únicos momentos verdadeiramente performativos deste espectáculo inteiramente criado com uma narração espirituosa e filosófica sobre o caminho que percorremos na vida. Like You Were Before ganhou um prémio Herald Angel em Edimburgo e regressa a uma antiquada, mas muito eficaz, forma de espectáculo, que é aquela em que se contam histórias.

0 Forest Fringe tem vindo a afirmar-se pela sua qualidade artística, e, sobretudo, pela sua proposta de gestão cultural. Esta forma de funcionamento aberta e gratuita regressa à base fundamental da criação: a vontade, por si só, de criar. O seu sucesso comprova que existem alternativas de excelência aos moldes de produção artística convencionais, incentivando também a uma prática mais económica e adequada aos tempos de crise que se vivem. 